\title{
ALGORYTM DYSTRYBUCJI ZNACZNIKÓW CZASOWYCH DLA POTRZEB SYNCHRONIZACJI DANYCH Z RÓŻNYCH SYSTEMÓW POMIAROWYCH
}

\author{
Radosław Wajman, Tomasz Jaworski, Pawel Fiderek, Robert Banasiak \\ Instytut Informatyki Stosowanej Politechniki Łódzkiej
}

Streszczenie. Badania opisane w artykule odnosza się do zakończonego projektu naukowo - badawczego, którego celem było zbudowanie systemu pomiarowego do wyznaczania udziatu faz w oparciu o trójwymiarowa tomografie pojemnościowa $3 D$ ECT. W ramach tych prac przewidziano ocene własności metrologicznych nowego systemu, w którym zastosowano równolegle wiele metod pomiarowych. Aby możliwe było dokładne porównanie wyników działań każdej z zastosowanych metod, potrzebne było opracowanie jednolitej ustugi znaczników czasowych do synchronizacji danych pomiarowych pochodzacych z różnych źródeł o różnej prędkości ich akwizycji. Artykuł opisuje zaprojektowany uniwersalny algorytm sieciowej ustugi dystrybucji znaczników czasowych.

Slowa kluczowe: synchronizacja danych pomiarowych, znaczniki czasowe

\section{ALGORITHM OF TIME STAMPS DISTRIBUTION FOR DATA SYNCHRONIZATION OF VARIOUS MEASUREMENT SYSTEMS}

\begin{abstract}
The described in this paper research refer to the finished project which aimed to build the measurement system for phase distribution calculation and two phase flow structure identification based on 3D ECT system. In the frame of this work the metrological validation of the measurement system was done where many of various measurement technics were applied parallel. In order to analyse the measurement results, there was a need to design the unified service of time stamps distribution for measurement data synchronization. The measured data were collected with different speed. This paper presents the designed universal network algorithm of the time stamps distribution.
\end{abstract}

Keywords: measurement data synchronization, time stamps

\section{Wprowadzenie}

Określenie udziału faz w przepływającej mieszaninie dwufazowej gaz-ciecz ma podstawowe znaczenie przy obliczaniu powierzchni kontaktu międzyfazowego, decydującej o procesach wymiany ciepła i masy oraz może być użyteczne przy określaniu oporów przepływu takiej mieszaniny. Badania opisane w artykule odnoszą się do zakończonego projektu naukowo - badawczego, którego celem było zbudowanie systemu pomiarowy do wyznaczania udziału faz w oparciu o trójwymiarowa tomografię pojemnościową 3D ECT (ang. three dimensional electrical capacitance tomography) [1]. W ramach tych prac przewidziano również ocenę metodami eksperymentalnymi własności metrologicznych tego systemu oraz analizę poszczególnych źródeł błędów na drodze odpowiednio zaplanowanej serii badań testowych [3]. W tym celu zostały zastosowane inne eksperymentalne metody wyznaczania udziału faz $w$ przepływie mieszaniny gaz-ciecz, jako metody porównawcze - między innymi wspomniane stanowisko badawcze do obserwacji przepływu przy pomocy kamery CCD [2] oraz metoda błyskawicznego zamykania odcinka pomiarowego rurociągu systemem dwóch szybkozamykających się zaworów pneumatycznych usytuowanych na początku i na końcu tego odcinka (metoda niemożliwa do zastosowania w warunkach przemysłowych).

Aby możliwe było dokładne porównanie wyników działań każdej z zastosowanych metod badania procentowego udziału faz, potrzebne było opracowanie jednolitej usługi znaczników czasowych do synchronizacji danych pomiarowych pochodzących z różnych źródeł o różnej prędkości ich akwizycji. Takiej synchronizacji czasowej wymagały:

- dane pomiarowe $\mathrm{z}$ trójwymiarowego tomografu pojemnościowego - ECT (prędkość akwizycji danych 12 ramek pomiarowych (równe jest 496 wartościom pojemności międzyelektrodowych) na sekundę),

- sekwencje obrazów rejestrowane przez kamerę CCD (30 obrazów na sekundę),

- nastawy urządzeń zasilających instalację badawczą (prędkość przepływu cieczy i gazu - prędkość zbierania danych ustalono na 2 pomiary na sekundę).

\section{Algorytm dystrybucji znaczników czasowych}

Każda $\mathrm{z}$ aplikacji rejestrujących wymienione w poprzednim rozdziale dane pomiarowe otrzymywała znaczniki czasowe, które były dostarczane $\mathrm{w}$ oparciu o czas wyznaczany przez jeden z komputerów i przypisywane do każdej wartości pomiarowej. Schemat sieci działań algorytmu usługi znaczników czasowych został przedstawiony na rysunku 1 . Zaprojektowana usługa działa w oparciu o lokalną sieć komputerową LAN i wysyła dane używając protokołu UDP (ang. User Datagram Protocol) na zadanym porcie 9055. Na jednym z komputerów w laboratorium pracuje aplikacja serwera czasu. Jej zadaniem jest udostępnianie klientom lokalnego czasu tego komputera. Każdy z klientów, zanim przystąpi do rejestrowania swoich danych pomiarowych, korzystając $z$ dodatkowej biblioteki DLL dołączanej do aplikacji pomiarowej zobligowany jest do wysłania do serwera żądania o podanie jego lokalnego czasu systemowego. $\mathrm{Na}$ podstawie tej wartości oraz swojego czasu lokalnego i czasu transmisji danych, wyznaczana jest różnica pomiędzy czasem klienta, a czasem serwera, która później służy do wyliczenia znacznika czasowego. Ten znacznik czasowy dodawany jest z kolei do każdego pomiaru rejestrowanego przez komputer klienta. Warto zaznaczyć, że usługa jest zaprojektowana $\mathrm{w}$ ten sposób, że dowolny komputer może zostać wybrany jako serwer czasu. Klient, nie znając adresu IP serwera, jest w stanie szybko go odnaleźć i nawiązać z nim komunikację sieciową, stosując tryb rozgłaszania w sieci komputerowej LAN.

\section{Zastosowanie znaczników czasowych}

W celu weryfikacji metody wyznaczania udziału faz z wykorzystaniem trójwymiarowego systemu ECT, przeprowadzono eksperyment polegający na jednoczesnej obserwacji przepływu techniką ECT, CCD oraz na pomiarze techniką szybkozamykających się zaworów. W trakcie trwania eksperymentu zapewnione były stałe warunki zasilania rurociągu cieczą oraz gazem. W konsekwencji uzyskano niezmienny charakter przepływu, którego struktury rejestrowano jednocześnie z pomocą komputerów pracujących w systemie tomografu oraz $\mathrm{z}$ kamerą $\mathrm{CCD}$, przy zapewnieniu synchronizacji czasowej obu urządzeń.

Ponieważ przeważnie długość struktur przepływu (pęcherzy gazowych i następujących po nich rzutów cieczy), które mogą zostać jednoznacznie zidentyfikowane, a co za tym idzie może być poprawnie zmierzony udział faz, jest znacznie większa niż zakres pomiarowy czujnika ECT, jak również obszar skanowania kamery CCD, należało zebrać pewną ilość pomiarów i analizować całą ich sekwencję. Rejestracja pomiarów trwała co najmniej 90s. To gwarantowało, że w danej sekwencji pomiarów udało się zarejestrować do kilku, nawet najdłuższych, powtarzających się struktur przepływu. Na rysunku 2 zamieszczono przykład jednego z przeprowadzonych eksperymentu. 
Rysunek 2 przedstawia zarejestrowane systemem ECT i kamerą CCD przebiegi przepływu rzutowego w sekcji poziomej. $\mathrm{Na}$ rysunku linią ciągłą zaznaczone zostały udziały fazy ciekłej i gazowej, wyznaczone na podstawie trójwymiarowych obrazów tomograficznych, zrekonstruowanych dla każdej zarejestrowanej ramki pomiarowej ECT (prędkość akwizycji danych to 12 ramek pomiarowych na sekundę; 1 ramka odpowiada 496 pomiarom pojemności). W dalszej kolejności udział fazy ciekłej lub gazowej został wyznaczony $\mathrm{w}$ oparciu o dane pochodzące $\mathrm{z}$ bloku wnioskowania rozmytego. Na rysunku 2 widać powtarzające się z dość dużą regularnością cykle rzutów w okresie co $160 \div 170$ tomograficznych ramek pomiarowych. Linią przerywaną zaznaczono udziały obu faz (ciekłej i gazowej), wyznaczone tym razem na podstawie analizy przeprowadzonej dla całej sekwencji obrazów, zarejestrowanych kamerą CCD (pomiary rejestrowane z prędkością 30 obrazów na sekundę).

Sekwencja obrazów CCD (w wyniku synchronizacji czasowej) dokładnie odpowiada pomiarom tomograficznym.

\section{Podsumowanie}

Synchronizacja czasowa okazała się niezwykle przydatna w przypadku zestawiania wyników pomiarowych z różnych systemów pomiarowych. Dzięki temu możliwe było dokładne odwzorowanie jednych danych pomiarowych (np. ECT), w innych (np. CCD), nawet dla tak dynamicznych procesów przemysłowych, jakimi są przepływy dwufazowe mieszanin gaz-ciecz.

Rysunek 2 przedstawia zarejestrowane systemem ECT i kamera CCD przebiegi przepływu rzutowego w sekcji poziomej. $\mathrm{Na}$ rysunku linią ciągłą zaznaczone zostały udziały fazy ciekłej i gazowej, wyznaczone na podstawie trójwymiarowych obrazów tomograficznych, zrekonstruowanych dla każdej zarejestrowanej ramki pomiarowej ECT (prędkość akwizycji danych to 12 ramek pomiarowych na sekundę; 1 ramka odpowiada 496 pomiarom pojemności). W dalszej kolejności udział fazy ciekłej lub gazowej został wyznaczony $\mathrm{w}$ oparciu o dane pochodzące $\mathrm{z}$ bloku wnioskowania rozmytego.

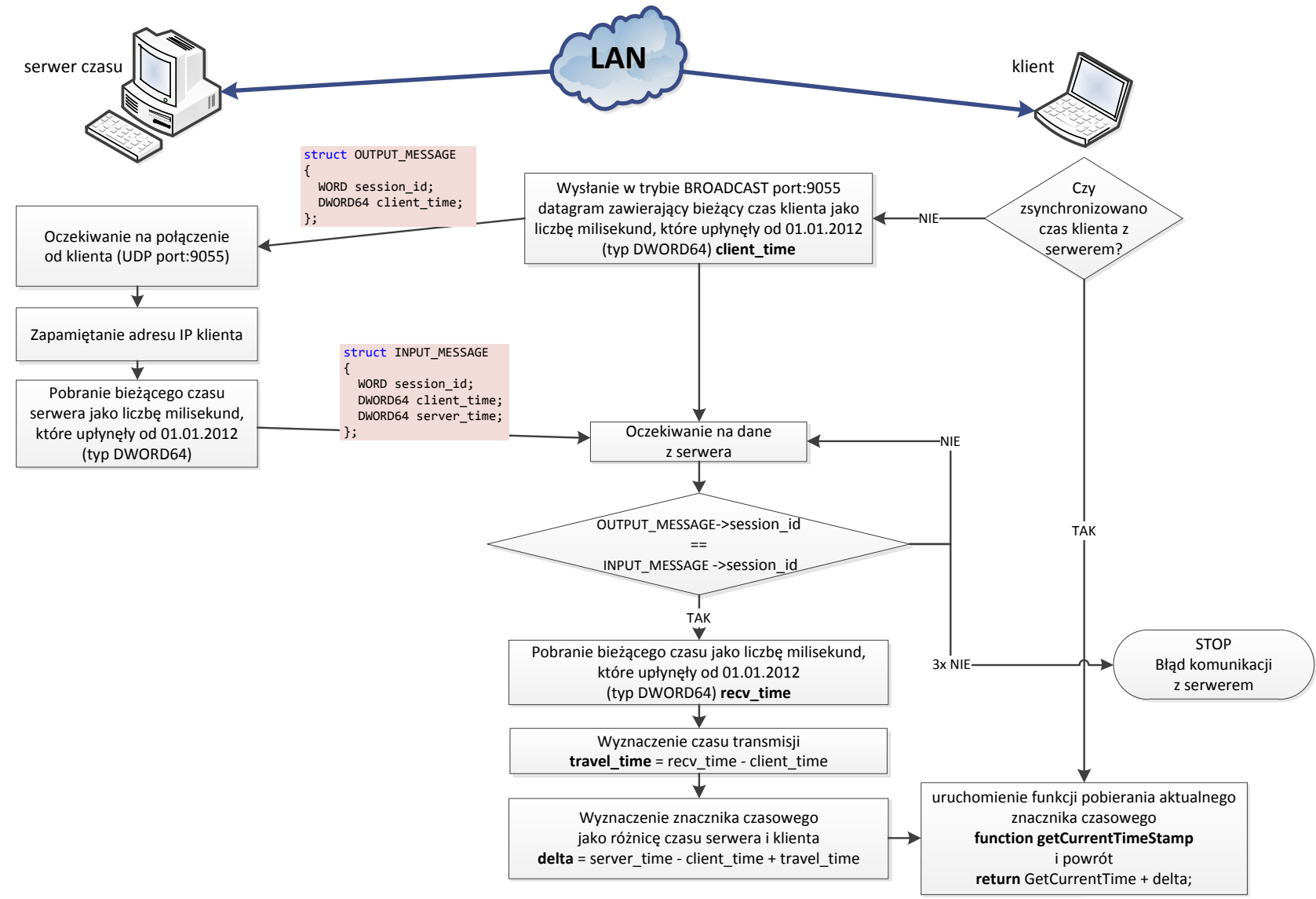

Rys. 1. Sieć działań algorytmu ustugi znaczników czasowych - w tym komunikacja sieciowa UDP serwer - użytkownik

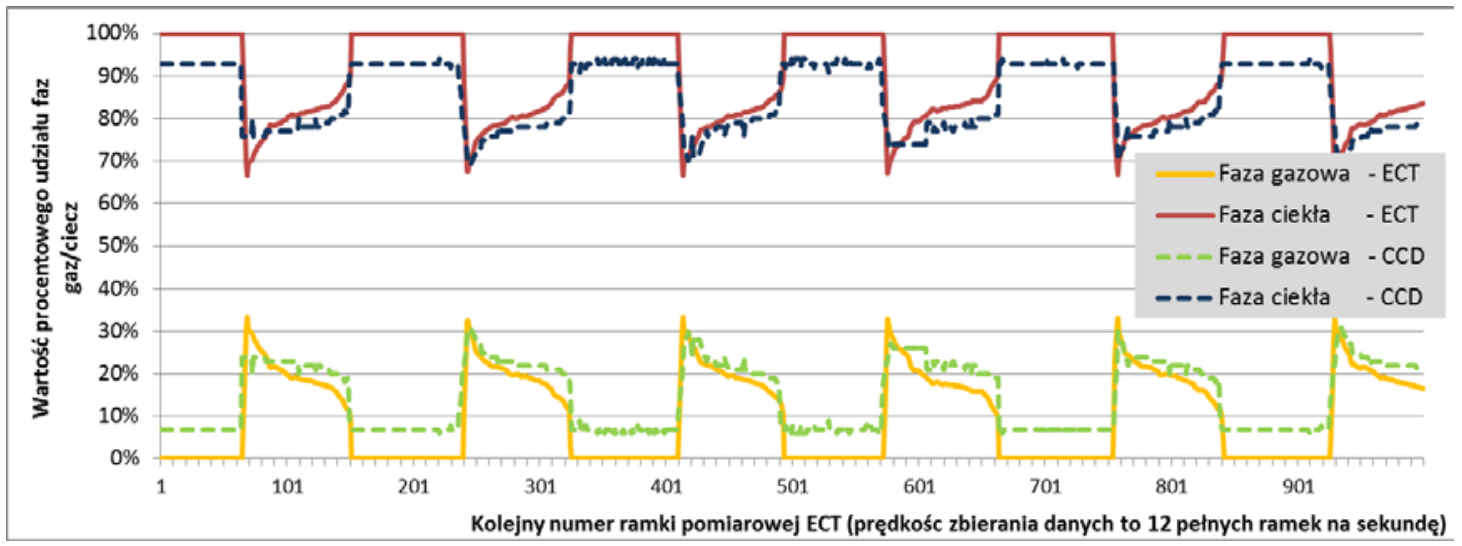

Rys. 2. Zarejestrowany systemem ECT $i$ kamera CCD przebieg przeptywu rzutowego $w$ sekcji poziomej z zaznaczeniem fazy cieklej $i$ gazowej 
$\mathrm{Na}$ rysunku 2 widać powtarzające się $\mathrm{z}$ dość dużą regularnością cykle rzutów w okresie co $160 \div 170$ tomograficznych ramek pomiarowych. Linią przerywaną zaznaczono udziały obu faz (ciekłej i gazowej), wyznaczone tym razem na podstawie analizy przeprowadzonej dla całej sekwencji obrazów, zarejestrowanych kamerą CCD (pomiary rejestrowane z prędkością 30 obrazów na sekundę).

Sekwencja obrazów CCD (w wyniku synchronizacji czasowej) dokładnie odpowiada pomiarom tomograficznym.

\section{Podsumowanie}

Synchronizacja czasowa okazała się niezwykle przydatna w przypadku zestawiania wyników pomiarowych z różnych systemów pomiarowych. Dzięki temu możliwe było dokładne odwzorowanie jednych danych pomiarowych (np. ECT), w innych (np. CCD), nawet dla tak dynamicznych procesów przemysłowych, jakimi są przepływy dwufazowe mieszanin gaz-ciecz.

\section{Podziękowania}

Prace opisane w ramach niniejszego artykułu są finansowane z rządowego projektu badawczego nr 4664/B/T02/2010/38.

\section{Literatura}

[1] Banasiak R., Wajman R., Fidos H., Fiderek P., Jaworski T., Nowakowski J., Sankowski D.: System trójwymiarowej tomografii pojemnościowej w zastosowaniu do wyznaczania udziału faz oraz identyfikacji struktur w przepływach mieszanin gaz-ciecz. IAPGOS, 2013, nr 3, 28-31.

[2] Fiderek P., Kucharski J.: A Computer Vision System for On-Line Two-Phase Gas-Liquid Flows Recognition Using Fuzzy Methods, Zeszyty naukowe AGH - Automatyka 15/3, 2011, s. 505-519.

[3] Wajman R., Fidos H., Fiderek P., Jaworski T., Nowakowski J., Sankowski D., Banasiak R.: Ocena metrologiczna systemu pomiarowego dla potrzeb wyznaczania udziału faz w przepływie mieszanin gaz-ciecz metodą tomografii pojemnościowej 3D. IAPGOS, 2013, nr 3, 49-54.
Dr inż. Radosław Wajman

e-mail: rwajman@kis.p.lodz.pl

Dr inż. Radosław Wajman jest adiunktem w Instytucie Informatyki Stosowanej Politechniki Łódzkiej. Prowadzone badania skupiają się nad zastosowaniem systemów trójwymiarowej tomografii pojemnościowej do nieinwazyjnego monitorowania, diagnozowania oraz automatycznego sterowania pracą przemysłowych instalacji przepływów dwu-fazowych.

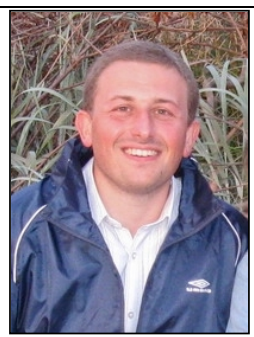

Mgr inż. Tomasz Jaworski

e-mail: tjaworski@kis.p.lodz.pl

Mgr inż. Tomasz Jaworski jest doktorantem $\mathrm{w}$ Instytucie Informatyki Stosowanej Politechniki Łódzkiej. W swoich pracach zajmuje się zagadnieniami związanymi $\mathrm{z}$ logika rozmytą oraz przetwarzaniem obrazów.

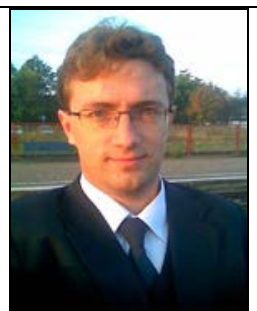

Mgr inż. Pawel Fiderek

e-mail: p.fiderek@kis.p.lodz.pl

Mgr inż. Paweł Fiderek jest doktorantem w Instytucie Informatyki Stosowanej Politechniki Łódzkiej. W swoich pracach zajmuje się zagadnieniami związanymi $\mathrm{z}$ tomografią komputerową, rozpoznawaniem obrazów oraz sztuczną inteligencją zwłaszcza logiką rozmytą.

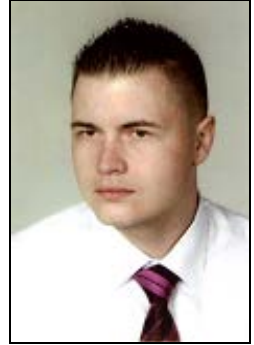

\section{Dr inż. Robert Banasiak}

e-mail: robert.banasiak@p.lodz.pl

Dr inż. Robert Banasiak jest adiunktem w Instytucie Informatyki Stosowanej Politechniki Łódzkiej. W swoich pracach zajmuje się przemysłowymi zastosowaniami elektrycznej tomografii procesowej, a w szczególności problematyką rekonstrukcji obrazów oraz modelowania numerycznego systemów tomografii pojemnościowej. Kierownik grantu 4664/B/T02/2010/38.

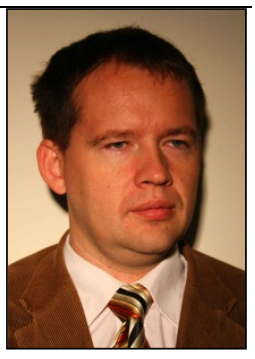

\section{5th Conference on Optical Fibers and Their Applications 29.01.2014 - 01.02.2014, Bialystok - Lipowy Most, Poland}

Conference on Optical Fibers and Their Applications is a long lasting, traditional event, organized since 1976. The purpose is summarizing the developments in the field of optical fiber technology and applications in this geographical region and worldwide. Bring together experts from different fields: academia, government laboratories, industry, telecom operators, and hardware/software vendors.

\section{Conference organizers}

Białystok University of Technology, Faculty of Electrical Engineering (Poland)

Polish Society of Theoretical and Applied Electrical Engineering(PTETiS)(Poland)

\section{IMPORTANT DATES}

15.11.2013 - Deadline for online registration and receipt of abstracts 15.12.2013 - Deadline for payment 29.01-01.02.2014 15th Conference on Optical Fibers and Their Applications

\section{Conference site} http://we.pb.edu.pl/swiatlowody
Contact Jacek Kusznier-swiatlowody@we.pb.edu.pl 